DOI 10.1007/s00702-002-0695-6

J Neural Transm (2002) 109: 1229-1240

_ Journal of _

Neural

Transmission

Printed in Austria

\title{
Stereospecific inhibition of monoamine uptake transporters by meta-hydroxyephedrine isomers
}

\author{
K. F. Foley ${ }^{1}$, M. E. Van Dort' ${ }^{2}$, M. K. Sievert ${ }^{3}$, A. E. Ruoho ${ }^{3}$, \\ and N. V. Cozzi ${ }^{1}$ \\ ${ }^{1}$ Department of Pharmacology, Brody School of Medicine, East Carolina University, \\ Greenville, NC, \\ ${ }^{2}$ Division of Nuclear Medicine, Department of Radiology, University of Michigan \\ Medical School, Ann Arbor, MI, and \\ ${ }^{3}$ Department of Pharmacology, University of Wisconsin Medical School, \\ Madison, WI, U.S.A.
}

Received October 22, 2001; accepted January 14, 2002

Published online June 28, 2002; (C) Springer-Verlag 2002

\begin{abstract}
Summary. Meta-hydroxyephedrine (HED) comprises four stereoisomers consisting of two enantiomeric pairs related to ephedrine and pseudoephedrine. HED is transported into adrenergic neurons and radiolabeled HED has been employed in positron emission tomography (PET) to image adrenergic neurons in vivo. To extend structure-activity analyses of binding sites within monoamine transporters and to determine which stereoisomer displayed the best selectivity for PET imaging applications, we tested the HED compounds for their abilities to inhibit $\left[{ }^{3} \mathrm{H}\right]$ neurotransmitter uptake into platelets, transfected cells, and chromaffin vesicles. We hypothesized that the HED compounds would be most potent at the norepinephrine transporter (NET) compared to the serotonin or dopamine transporters and that the $1 \mathrm{R}$ diastereomers would be more effective than $1 \mathrm{~S}$ diastereomers. Supporting the hypotheses, all stereoisomers were most potent at the NET and the $1 \mathrm{R}, 2 \mathrm{~S}$ stereoisomer was the most potent inhibitor overall. However, the $1 \mathrm{~S}, 2 \mathrm{R}$ isomer may be preferred for PET applications because of better selectivity among the transporters and reduced neuronal recycling.
\end{abstract}

Keywords: m-hydroxyephedrine, dopamine transporter (DAT), norepinephrine transporter (NET), serotonin transporter (SERT), vesicle monoamine transporter (VMAT2), positron emission tomography (PET), stereoisomer, substrate, noradrenaline.

\section{Introduction}

Following their release as chemical neurotransmitters, the biogenic amines serotonin, dopamine, and norepinephrine are cleared from the synapse 
via their respective sodium- and chloride-dependent plasma membrane uptake transporters SERT, DAT, and NET. These transporters belong to a large family of uptake carriers with common structural features (Graham and Langer, 1992; Rudnick and Clark, 1993; Kanner, 1994; Worrall and Williams, 1994), but the SERT, DAT, and NET differ in their substrate:ion stoichiometry (Rudnick, 1998). The transporters also differ in their substrate selectivity, inhibitor sensitivity, and transport kinetics ( $\mathrm{Gu}$ et al., 1994). Once the biogenic amines have been translocated into the neuron by the plasma membrane transporters, they are packaged into synaptic vesicles by the neuronal vesicle transporter VMAT2 (Feany et al., 1992; Liu et al., 1992). Like the plasma membrane carriers, VMAT2 is predicted to have 12 transmembrane domains (TMDs), with cytosolic amino and carboxy termini. Unlike the plasma membrane carriers, VMAT2 does not require sodium or chloride ions. Rather, the influx of neurotransmitter into the vesicle is coupled to the efflux of protons; the vesicle is supplied with protons through the action of a vesicle membrane ATP-driven proton pump (Njus, 1983; Johnson, 1987).

In addition to translocating their respective biogenic amines, the monoamine uptake transporters will also translocate certain exogenous compounds. These compounds include phenylalkylamines such as metaraminol, 3,4methylenedioxymethamphetamine (MDMA), and fenfluramine (Schuldiner et al., 1993; Crespi et al., 1997; Rothman et al., 1999). The fact that the monoamine transporters can tolerate some structural diversity among substrates has been exploited in the development of drugs that can act as surrogates for the biogenic amines. Meta-hydroxyephedrine (HED), for example, is a catecholamine substrate analog that is accumulated within adrenergic neurons via the NET (Rosenspire et al., 1990). HED comprises two enantiomeric pairs related to ephedrine (erythro configuration) or pseudoephedrine (threo configuration) (Fig. 1). A radiolabeled form of one of the stereoisomers, 1R,2S [ $\left.{ }^{11} \mathrm{C}\right] \mathrm{HED}$, has been employed as a positron emission tomography (PET) tracer to image adrenergic neurons in vivo. $1 \mathrm{R}, 2 \mathrm{~S}\left[{ }^{11} \mathrm{C}\right] \mathrm{HED}$ was used to study the NET-mediated neuronal uptake kinetics of cardiac adrenergic terminals in an experimental model of ischemia, in disease states such as myocardial infarction and diabetic neuropathy, and in transplanted human heart (Schwaiger et al., 1991; Allman et al., 1993a,b; DeGrado et al., 1993; Di Carli et al., 1997).

Our laboratory employs structure-activity relationship studies of monoamine transporter substrate analogs as one approach to characterizing drug binding sites within these carrier proteins. Through their ability to competitively inhibit the uptake of endogenous neurotransmitters, substrate analogs can reveal whether the monoamine carriers prefer certain structural features; these preferences are indicative of the biochemical microenvironment within the substrate binding sites of the transporters. HED is well-suited to these kinds of studies because HED comprises four stereoisomers that have identical chemical structures but differ only in the three-dimensional configuration of the amino and hydroxyl groups on the alkylamine side-chain (Fig. 1). Any observed differences in potency among the HED isomers will indicate 
Erythro series<smiles>CNC(C)C(O)c1cccc(O)c1</smiles><smiles>[R2][C](C)[C@H](O)c1cccc(O)c1</smiles>

Threo series<smiles>CNC(C)C(O)c1cccc(O)c1</smiles><smiles>CNC(C)C(O)c1cccc(O)c1</smiles>

Fig. 1. Chemical structures of meta-hydroxyephedrine stereoisomers

what parts of the ligand are important for molecular recognition by the transporters and will reflect the geometry of the substrate binding pocket within the transporters. Due to the current unavailability of the crystal structure of the transporters, this approach allows one to construct pharmacophore-based models of the substrate binding sites. These models have predictive power in drug design and must ultimately be in harmony with the three-dimensional structures of the transporters, if they are solved.

To extend our structure-activity studies of monoamine transporter ligands and to determine which of the HED isomers displays the best transporter selectivity for PET imaging applications, all four stereoisomers of HED were synthesized and tested for their abilities to inhibit monoamine neurotransmitter uptake in vitro. Among the plasma membrane uptake transporters, we hypothesized that the HED compounds would be most potent at the NET because of their structural similarity to norepinephrine. We further hypothesized that the $1 \mathrm{R}$ diastereomers would be more potent than the $1 \mathrm{~S}$ diastereomers because norepinephrine itself has R stereochemistry at this position. To test for selectivity among the monoamine transporters, we examined the ability of each of the HED isomers to inhibit tritiated monoamine uptake into human platelets (SERT) or cultured cells individually expressing the cloned human DAT or NET. We also tested the HED isomers for the ability to inhibit $\left[{ }^{3} \mathrm{H}\right]$ serotonin uptake into bovine chromaffin vesicles via VMAT2. By comparing the $\mathrm{IC}_{50}$ values for monoamine uptake inhibition among the four stereoisomers, we hoped to identify structure-related differences in potency and selectivity among the monoamine transporters. In this study, we were able to detect such differences among the HED isomers. These observations should aid in modeling the transporter substrate binding sites and in the rational design of transporter-selective drugs for imaging studies and new drugs to treat diseases, such as depression, which have been associated with aberrant transporter function. 


\section{Materials and methods}

\section{Drugs and reagents}

The chemical synthesis of the four HED isomers has been reported previously by one of us (Van Dort and Tluczek, 2000). Briefly, a mixture containing the four stereoisomers of meta-hydroxyphenylpropanolamine (MHPA) was synthesized in $20 \%$ overall yield by a seven-step synthetic route from propiophenone. The individual MHPA stereoisomers were isolated from the mixture using semipreparative chiral high pressure liquid chromatography (HPLC) as described (Van Dort, 1999). Each stereoisomer of MHPA was converted to its respective carbamate derivative, which was then reduced to the respective HED stereoisomer with lithium aluminum hydride in refluxing tetrahydrofuran. After chromatographic purification, the HED free bases were converted to the hydrochloride salts and recrystalized. The HED isomers were characterized with respect to their physical properties by melting point (Thomas Hoover apparatus) and optical rotation (Perkin-Elmer 241 polarimeter; $589 \mathrm{~nm}$ ) determinations. Chemical structures were confirmed by ${ }^{1} \mathrm{H}$ NMR spectroscopy (Bruker WM-360; 360 MHz) and by high-resolution mass spectrometry (Finnigan UG70-250-S). For uptake inhibition assays, $10 \mathrm{mM}$ stock solutions of the HED isomers were individually prepared in deionized water.

$\left[{ }^{2} \mathrm{H}\right]$ Serotonin $\left(\right.$ specific activity $=36.4 \mathrm{Ci} / \mathrm{mmol}$ ), $\left[{ }^{3} \mathrm{H}\right]$ dopamine $($ specific activity $=$ $59.1 \mathrm{Ci} / \mathrm{mmol}$ ), and $\left[{ }^{3} \mathrm{H}\right]$ norepinephrine (specific activity $=55.0 \mathrm{Ci} / \mathrm{mmol}$ ) were purchased from New England Nuclear, Boston, MA. Cell culture media and antibiotics were purchased from Life Technologies, Gaithersburg, MD. Fetal bovine serum was obtained from Hyclone, Logan, UT. Pargyline, reserpine, buffer salts, and miscellaneous chemicals were acquired from Aldrich Chemical, Milwaukee, WI.

\section{Serotonin plasma membrane uptake transporter: $\left[{ }^{3} \mathrm{H}\right]$ serotonin uptake into human platelets}

To test drug effects on SERT-mediated $\left[{ }^{3} \mathrm{H}\right]$ serotonin accumulation, human donor platelets were used. Outdated platelets were obtained from the blood bank at Pitt County Memorial Hospital, Greenville, NC. Platelets were prepared for uptake assays as previously described (Cozzi et al., 1999). After two washes, the final pellet was suspended in $30 \mathrm{ml}$ ice-cold Krebs-Ringer-HEPES (KRH) buffer containing (mM): NaCl (124.0), KCl (2.9), $\mathrm{MgSO}_{4}$ (1.3), $\mathrm{KH}_{2} \mathrm{PO}_{4}$ (1.2), $\mathrm{CaCl}_{2}$ (2.4), d-glucose (5.2), HEPES (25.0), sodium ascorbate (0.1), pargyline (0.1); $\mathrm{pH}=7.4$. The suspension was then stored on ice until use. For assays, a $490 \mu \mathrm{l}$ aliquot of the platelet suspension was added to glass tubes containing either $5 \mu \mathrm{l}$ meta-hydroxyephedrine isomer solution (various concentrations) or $5 \mu \mathrm{KRH}$ (for total and nonspecific determinations). The assay tubes were preincubated in a $37^{\circ} \mathrm{C}$ shaking water bath for $5 \mathrm{~min}$. The tubes were then returned to the ice bath and chilled for $15 \mathrm{~min} .\left[{ }^{3} \mathrm{H}\right]$ Serotonin was added to each tube $(5 \mu \mathrm{l}$ of stock solution; final concentration, $15 \mathrm{nM}$ ), giving a total incubation volume of $500 \mu \mathrm{l}$. All assay tubes except nonspecific tubes were returned to the $37^{\circ} \mathrm{C}$ shaking water bath for $5 \mathrm{~min}$ to initiate neurotransmitter uptake. Uptake was terminated by chilling the test tubes in the ice bath. After adding $3 \mathrm{ml}$ ice-cold $150 \mathrm{mM} \mathrm{NaCl}$, each assay tube was vacuum filtered through glass fiber filters (Whatman GF/B) pretreated with $0.1 \%$ polyethyleneimine (PEI). Filters were washed with $2 \times 3 \mathrm{ml}$ ice-cold $150 \mathrm{mM} \mathrm{NaCl}$, allowed to dry briefly under vacuum, then placed in liquid scintillation vials. Scintillation cocktail $(3 \mathrm{ml})$ was added and the vials were sealed, vortexed, and allowed to stand overnight. Radioactivity was measured using liquid scintillation counting (Packard Tri-Carb 1600 CA). Specific uptake was defined as uptake at $37^{\circ} \mathrm{C}$ minus uptake at $0^{\circ} \mathrm{C}$ in the absence of drugs.

\section{Dopamine plasma membrane uptake transporter: $\left[{ }^{3} \mathrm{H}\right]$ dopamine uptake into transfected cells}

Human embryonic kidney cells stably expressing the human dopamine transporter (293DAT) were a gift from Dr. M. Reith (University of Illinois). Cells were maintained 
in a humidified atmosphere $\left(5 \% \mathrm{CO}_{2}\right.$ in air) in selective culture medium: Dulbecco's Modified Eagle's Medium (DMEM) containing 10\% fetal bovine serum and antibiotics $(100 \mathrm{U} / \mathrm{ml}$ penicillin, $100 \mu \mathrm{g} / \mathrm{ml}$ streptomycin, $2 \mu \mathrm{g} / \mathrm{ml}$ puromycin). For assays, the DMEM was aspirated from $3 \times 100 \mathrm{~mm}$ dishes of confluent cells and the cells were washed three times with $37^{\circ} \mathrm{C} \mathrm{KRH}$, then harvested in $30 \mathrm{ml}$ total ice-cold $\mathrm{KRH}$. The cells were suspended using a polytron (setting $4,5 \mathrm{sec}$ ). The ability of the test drugs to inhibit $\left[{ }^{3} \mathrm{H}\right]$ dopamine uptake was measured as follows: a $490 \mu \mathrm{l}$ aliquot of the 293DAT cell suspension was added to glass tubes, then $5 \mu l$ of meta-hydroxyephedrine isomer (various concentrations), $5 \mu \mathrm{KRH}$ (for total determinations), or $5 \mu \mathrm{l} 10 \mathrm{mM}$ cocaine hydrochloride (for nonspecific determinations; final concentration, $100 \mu \mathrm{M}$ ) was added to the appropriate tubes. The tubes were preincubated with shaking at $37^{\circ} \mathrm{C}$ for $10 \mathrm{~min}$, then returned to the ice bath and chilled for $15 \mathrm{~min}$. Five $\mu \mathrm{l}$ of $\left[{ }^{3} \mathrm{H}\right]$ dopamine (final concentration, $15 \mathrm{nM}$ ) was added to each tube and the assay tubes were incubated with shaking at $37^{\circ} \mathrm{C}$ for $10 \mathrm{~min}$ to induce neurotransmitter uptake. Uptake was quenched by chilling the test tubes in the ice bath, then the assay tubes were diluted, filtered, worked-up, and counted as described for platelets.

\section{Norepinephrine plasma membrane uptake transporter: $\left[{ }^{3} \mathrm{H}\right]$ norepinephrine uptake into transfected cells}

C6 rat glial cells stably expressing the human norepinephrine transporter (C6NET) were a gift from Dr. Susan Amara (Oregon Health Sciences University). Cells were maintained in a humidified atmosphere $\left(5 \% \mathrm{CO}_{2}\right.$ in air) in selective culture medium: DMEM containing $10 \%$ fetal bovine serum and antibiotics $(100 \mathrm{U} / \mathrm{ml}$ penicillin, $100 \mu \mathrm{g} / \mathrm{ml}$ streptomycin, $100 \mu \mathrm{g} / \mathrm{ml}$ geneticin). For assays, the DMEM was removed from $3 \times 100 \mathrm{~mm}$ dishes of confluent cells and the cells were washed with phosphate buffered saline, $\mathrm{pH}=7.1$. The cells were then treated with trypsin/EDTA and split into 24-well plates. This allowed triplicate assays for total uptake, nonspecific uptake, and six drug concentrations per plate. Each well contained $1 \mathrm{ml}$ of culture medium. Cells were grown overnight to confluency. The ability of the HED isomers to inhibit $\left[{ }^{3} \mathrm{H}\right]$ norepinephrine uptake was measured as follows: the DMEM was aspirated from the 24-well plates, the cells were washed with $3 \times 2 \mathrm{ml} 37^{\circ} \mathrm{C} \mathrm{KRH}$, and $490 \mu l 37^{\circ} \mathrm{C} \mathrm{KRH}$ was added to each well. This was followed by the addition of $5 \mu \mathrm{KRH}$ (for total determinations), $5 \mu \mathrm{l} 10 \mathrm{mM}$ desipramine (for nonspecific determinations; final concentration, $100 \mu \mathrm{M}$ ), or $5 \mu \mathrm{l}$ of test drug solution. The plates were preincubated at $37^{\circ} \mathrm{C}$ for $10 \mathrm{~min}$, then $5 \mu$ lof $\left[{ }^{3} \mathrm{H}\right]$ norepinephrine (final concentration, $15 \mathrm{nM}$ ) was added to each well to initiate uptake. Uptake was allowed to proceed for $10 \mathrm{~min}$, then the incubation buffer was discarded and the cells were washed with $3 \times 2 \mathrm{ml}$ ice-cold $\mathrm{KRH}$. The cells were solubilized in $500 \mu 137^{\circ} \mathrm{C} 1 \%$ sodium dodecyl sulfate, then the solubilized well contents were transferred to liquid scintillation vials containing $3 \mathrm{ml}$ scintillation cocktail. Radioactivity was measured as described for platelets.

\section{Vesicular monoamine transporter (VMAT2): $\left[{ }^{3} H\right]$ serotonin uptake into bovine chromaffin granules}

Drug effects on VMAT2-mediated [ $\left.{ }^{3} \mathrm{H}\right]$ serotonin accumulation were monitored in bovine chromaffin vesicles. Vesicles were prepared according to our previously reported procedure (Cozzi et al., 1999). For uptake assays, chromaffin vesicle ghosts were diluted in assay buffer containing (mM): sucrose (300), $\operatorname{HEPES~(10),~ATP~(5),~} \mathrm{MgSO}_{4}(5), \mathrm{pH}=7.8$ to a final volume of $0.5 \mathrm{ml}$. Assays were performed in triplicate. The samples were incubated at $37^{\circ} \mathrm{C}$ for $10 \mathrm{~min}$ and then cooled on ice for $\left.10 \mathrm{~min} .{ }^{3} \mathrm{H}\right]$ Serotonin was then added to a final concentration of $20 \mathrm{nM}$ and the samples were incubated for $5 \mathrm{~min}$ at $37^{\circ} \mathrm{C}$ to initiate uptake. Uptake was tested in the absence or presence of the test drugs added to the assay buffer; nonspecific uptake was defined by $10 \mu \mathrm{M}$ reserpine. After the $5 \mathrm{~min}$ uptake incubation, samples were transferred to an ice bath and collected onto glass fiber 
filters (Whatman GF/B, pretreated with $0.1 \%$ PEI) using a Brandel cell harvester (model M-48T). The filters were washed with $6 \times 1 \mathrm{ml}$ ice-cold assay buffer minus ATP and $\mathrm{MgSO}_{4}$. Filters were transferred to scintillation vials and $10 \mathrm{ml}$ scintillation cocktail was added. Radioactivity was measured as described for platelets.

\section{Data analysis and statistics}

All HED isomers were screened for $\left[{ }^{3} \mathrm{H}\right]$ monoamine uptake inhibition at $30 \mu \mathrm{M}$. If at least one HED compound inhibited uptake by $50 \%$ or more at the screening concentration, the $\mathrm{IC}_{50}$ values \pm standard error of the mean (S.E.M.) for all four HED isomers were determined from displacement curves from at least three experiments using six drug concentrations, each run in triplicate. Data were transformed from dpm to percent specific uptake and fitted to a four-parameter logistic curve using commercial computer software. Multiple comparisons of the HED stereoisomer $\mathrm{IC}_{50}$ values were performed using ANOVA followed by a Student-Newman-Keuhls t-test using commercial computer software (GraphPad, San Diego, CA) with $\mathrm{P}<0.05$ considered significant.

\section{Results}

In C6NET cells, specific $\left[{ }^{3} \mathrm{H}\right]$ norepinephrine uptake was $>90 \%$ of total uptake as defined by $100 \mu \mathrm{M}$ desipramine. All of the HED stereoisomers passed our $30 \mu \mathrm{M}$ screening criterion at the NET. Dose-response curves for drug inhibition of $\left[{ }^{3} \mathrm{H}\right]$ norepinephrine uptake are shown in Fig. 2 with $\mathrm{IC}_{50}$ values summarized in Table 1. The inhibition curves had slope coefficients of unity, indicating that the HED isomers acted at a single site on the NET. The 1R,2S isomer was the most potent inhibitor of $\left[{ }^{3} \mathrm{H}\right]$ norepinephrine accumulation $(\mathrm{P}<0.05)$ with an $\mathrm{IC}_{50}$ value of $0.42 \pm 0.04 \mu \mathrm{M}$. The $1 \mathrm{~S}, 2 \mathrm{R}$ and $1 \mathrm{~S}, 2 \mathrm{~S}$ isomers were intermediate in potency, while the $1 \mathrm{R}, 2 \mathrm{R}$ isomer was the least potent isomer (all $\mathrm{P}<0.05$; see Table 1 ). Thus, the rank order of potency among the HED stereoisomers at the NET is: $1 \mathrm{R}, 2 \mathrm{~S}>1 \mathrm{~S}, 2 \mathrm{~S}=1 \mathrm{~S}, 2 \mathrm{R}>1 \mathrm{R}, 2 \mathrm{R}$.

Cocaine-sensitive $\left[{ }^{3} \mathrm{H}\right]$ dopamine uptake was $\geq 65 \%$ of total uptake in 293DAT cells. Dose-response curves for drug inhibition of $\left[{ }^{3} \mathrm{H}\right]$ dopamine uptake were determined after screening at $30 \mu \mathrm{M}$. Like drug effects at the

Table 1. $\mathrm{IC}_{50}$ values $(\mu \mathrm{M})$ for drug inhibition of transporter-mediated monoamine uptake

\begin{tabular}{lcccccc}
\hline Drug & NET & DAT & SERT $^{b}$ & VMAT2 & \multicolumn{2}{l}{ Selectivity ratios } \\
\cline { 6 - 7 } & & & & & DAT:NET & VMAT2:NET \\
\hline & & & & & & \\
1R,2S HED & $0.422 \pm 0.04$ & $4.34 \pm 1.4$ & $>30$ & $23.7 \pm 2.2$ & 10.3 & 56.2 \\
1S,2S HED & $1.18 \pm 0.26$ & $5.60 \pm 0.88$ & $>30$ & $58.6 \pm 6.5$ & 4.7 & 49.7 \\
1R,2R HED & $6.95 \pm 1.1$ & $20.8 \pm 2.1$ & $>30$ & $144 \pm 18$ & 3.0 & 20.7 \\
1S,2R HED & $1.03 \pm 0.10$ & $43.2 \pm 5.7$ & $>30$ & $101 \pm 11$ & 41.9 & 98.1 \\
\hline
\end{tabular}

a The ability of test drugs to inhibit $\left[{ }^{3} \mathrm{H}\right]$ monoamine accumulation was examined as described under Materials and methods. HED compounds were tested with 6 concentrations, each run in triplicate. The data from 3-5 experiments were combined and the $\mathrm{IC}_{50}$ values \pm S.E.M. were calculated by curve fitting. ${ }^{b}$ Percent inhibition of $\left[{ }^{3} \mathrm{H}\right]$ serotonin uptake at $30 \mu \mathrm{M}: 1 R, 2 S H E D=31.3 \pm 6.3 \% ; 1 S, 2 S H E D=21.1 \pm 7.8 \% ; 1 R, 2 R$ $H E D=14.1 \pm 8.3 \% ; 1 S, 2 R H E D=$ no inhibition 


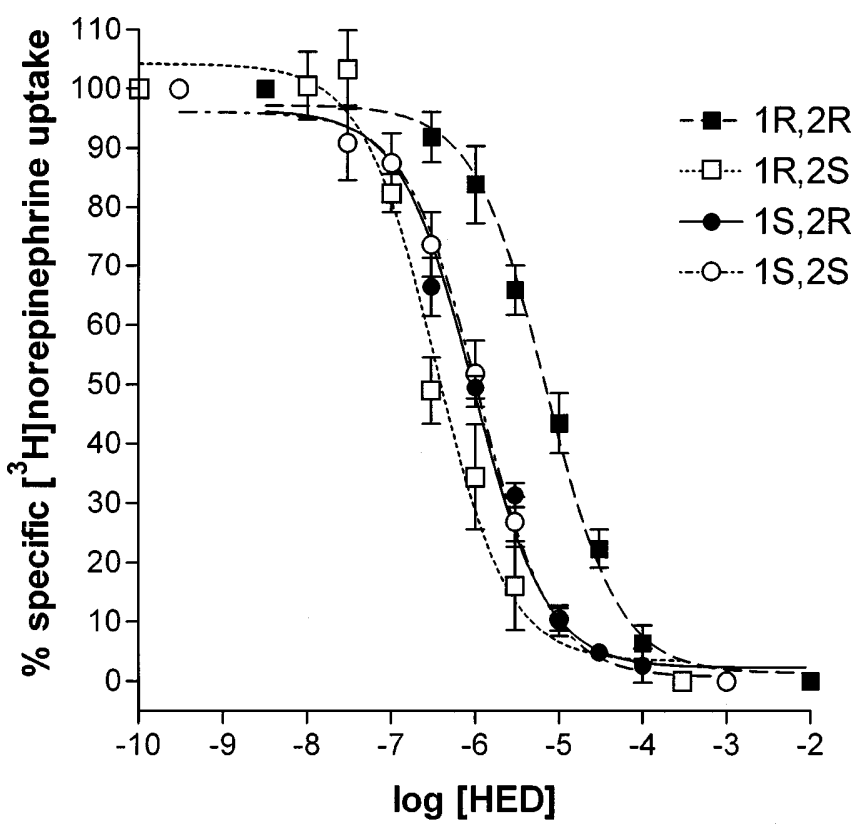

Fig. 2. Drug inhibition of NET-mediated $\left[{ }^{3} \mathrm{H}\right]$ norepinephrine uptake. The ability of test drugs to inhibit accumulation of $15 \mathrm{nM}\left[{ }^{3} \mathrm{H}\right]$ norepinephrine was examined in cultured cells expressing the human NET. Specific uptake was defined by $100 \mu \mathrm{M}$ desipramine. Data are the mean \pm S.E.M. of 3-6 determinations, each run in triplicate. Data were fitted to a four-parameter logistic curve for $\mathrm{IC}_{50}$ determination and plotting

NET, all the DAT inhibition curves had slope coefficients that did not differ from unity. All of the HED isomers except the 1S,2R configuration exhibited $\mathrm{IC}_{50}$ values below $30 \mu \mathrm{M}$. The $1 \mathrm{R}, 2 \mathrm{~S}$ and $1 \mathrm{~S}, 2 \mathrm{~S}$ HED configurations were the most potent $(\mathrm{P}<0.01)$ at the DAT and had similar $\mathrm{IC}_{50}$ values (Table 1$)$. The $1 \mathrm{R}, 2 \mathrm{R}$ configuration was four-fold less potent $(\mathrm{P}<0.01)$ with an $\mathrm{IC}_{50}$ of $20.8 \pm 2.1 \mu \mathrm{M}$. The $1 \mathrm{~S}, 2 \mathrm{R}$ stereoisomer was the least potent drug in the series $(\mathrm{P}<0.01$; Table 1$)$. The rank order of potency among the HED isomers at the DAT is $1 \mathrm{R}, 2 \mathrm{~S}=1 \mathrm{~S}, 2 \mathrm{~S}>1 \mathrm{R}, 2 \mathrm{R}>1 \mathrm{~S}, 2 \mathrm{R}$.

The uptake of $\left[{ }^{3} \mathrm{H}\right]$ serotonin by platelets in the absence of test drugs was typically $>90 \%$ specific. None of the test drugs inhibited specific $\left[{ }^{3} \mathrm{H}\right]$ serotonin uptake by at least $50 \%$ at the $30 \mu \mathrm{M}$ screening concentration, so $\mathrm{IC}_{50}$ values were not calculated. However, the percent inhibition of specific $\left[{ }^{3} \mathrm{H}\right]$ serotonin uptake was calculated. The percent inhibition at $30 \mu \mathrm{M}$ drug concentration for each isomer is as follows: $1 \mathrm{R}, 2 \mathrm{~S}=31.3 \pm 6.3 \% ; 1 \mathrm{~S}, 2 \mathrm{~S}=21.1$ $\pm 7.8 \% ; 1 \mathrm{R}, 2 \mathrm{R}=14.1 \pm 8.3 \% ; 1 \mathrm{~S}, 2 \mathrm{R}=$ no inhibition. Just as at the NET and the DAT, the HED isomer with the 1R,2S configuration appeared to be the most potent inhibitor at the SERT; the rank order of potency of the HED isomers at the SERT is $1 \mathrm{R}, 2 \mathrm{~S}>1 \mathrm{~S}, 2 \mathrm{~S}>1 \mathrm{R}, 2 \mathrm{R}>1 \mathrm{~S}, 2 \mathrm{R}$.

The VMAT2-mediated uptake of $\left[{ }^{3} \mathrm{H}\right]$ serotonin in chromaffin ghosts was $>90 \%$ specific as defined by $10 \mu \mathrm{M}$ reserpine. In this system, the $1 \mathrm{R}, 2 \mathrm{~S} H E D$ isomer was again the most potent inhibitor of uptake $(\mathrm{P}<0.05)$ with an $\mathrm{IC}_{50}$ of $23.7 \pm 2.2 \mu \mathrm{M}$. The remaining drugs were substantially less potent, with $\mathrm{IC}_{50}$ 
values as high as $144 \mu \mathrm{M}$ (Table 1 ). The rank order of potency at VMAT2 is therefore $1 \mathrm{R}, 2 \mathrm{~S}>1 \mathrm{~S}, 2 \mathrm{~S}>1 \mathrm{~S}, 2 \mathrm{R}>1 \mathrm{R}, 2 \mathrm{R}$.

\section{Discussion}

The synthesis of the individual HED stereoisomers on a milligram scale has allowed us to test these compounds for their inhibition potencies at the monoamine uptake transporters. In the present study, we compared the abilities of the four stereoisomers of HED to inhibit $\left[{ }^{3} \mathrm{H}\right]$ monoamine accumulation via the plasma membrane uptake transporters and via VMAT2. We expected to see differences in potency among the HED isomers at the plasma membrane transporters due to the different configurations of the side-chain amine group. Among monoamine ligands, the (protonated) amine nitrogen has been proposed to form an ionic bond with a conserved aspartate residue in TMD1 of the plasma membrane transporters (Kitayama et al., 1992; Barker et al., 1999). We thought that this interaction would be sensitive to the spatial placement of the amine. Our expectation was borne out at the SERT and DAT: the stereochemistry of the side-chain amine group dominates the binding interaction in these transporters. The $2 \mathrm{~S}$ diastereomers were more potent than the $2 \mathrm{R}$ diastereomers, regardless of the configuration at the 1-position (Table 1). In addition to a potentially more productive electronic alignment with the conserved aspartic acid residue, the $2 \mathrm{~S}$ isomers may also benefit from a favorable steric environment for binding (e.g. complementary pocket), or through some combination of these. The stereochemistry at the 1-position played a lesser, but still significant, role: the $1 \mathrm{R}$ diastereomers were more potent than the $1 \mathrm{~S}$ diastereomers, once the effect of the 2-position is taken into account. Thus, despite the absence of stereogenic centers in serotonin and dopamine, the substrate binding domains within the SERT and DAT favor certain topological or electronic configurations in ligand side chains. The fact that the HED isomers, like dopamine, are phenylalkylamines may partly explain the increased potency among these drugs at the DAT compared to the SERT; the SERT would be expected to prefer indolealkylamine substrates. Nevertheless, there exist phenylalkylamines that are quite potent competitive inhibitors of SERT-mediated $\left[{ }^{3} \mathrm{H}\right]$ serotonin uptake (Huang et al., 1992; Monte et al., 1993; Crespi et al., 1997).

We hypothesized that the HED compounds would be most potent at the NET because of their structural similarity to norepinephrine i.e. the HED isomers and norepinephrine all contain a hydroxyl moiety on the side-chain. Supporting our hypothesis, each of the HED compounds exhibited higher affinities for the NET than for any of the other transporters (Table 1). In particular, the HED compounds were more effective inhibitors at the NET than at the highly homologous DAT and SERT proteins. A reasonable explanation for this observation stems from the fact that while the NET will effectively transport both norepinephrine and dopamine, the DAT and SERT are not efficient transporters of norepinephrine (Pacholczyk et al., 1991; Giros et al., 1992). We propose that in norepinephrine, the side-chain hydroxyl is an essential feature in the molecular exclusion of norepinephrine by the DAT 
and the SERT, either through an unfavorable electrostatic interaction involving the side-chain hydroxyl group or through steric occlusion within the substrate binding site. The HED compounds, like norepinephrine, incorporate a hydroxyl group at the side-chain 1-position and would therefore be expected to encounter the same interference at the DAT and SERT as norepinephrine, leading to the observed higher affinity at the NET compared to the DAT and the SERT. The presence of the side-chain hydroxyl also imparts chirality to the carbon at the 1-position, and, in norepinephrine, the stereochemistry is R. We hypothesized that both of the HED diastereomers with the 1R configuration would more closely mimic norepinephrine and would therefore be the most potent inhibitors of $\left[{ }^{3} \mathrm{H}\right]$ norepinephrine uptake. As our data shows, the most potent inhibitor of $\left[{ }^{3} \mathrm{H}\right]$ norepinephrine uptake does have $1 \mathrm{R}$ stereochemistry. This is the HED isomer with the $1 \mathrm{R}, 2 \mathrm{~S}$ configuration. This drug was the most potent inhibitor of monoamine uptake across all the plasma membrane transporters, and has an $\mathrm{IC}_{50}$ of only $0.42 \mu \mathrm{M}$ at the NET (Table 1 ). Continuing the trend observed at the SERT and DAT, the 1R,2S diastereomer was also more potent (about 16-fold) than the $1 \mathrm{R}, 2 \mathrm{R}$ configuration. However, the difference in potency between the 2-position isomers is not manifested in the 1S HED stereopair: when the stereochemistry is 1S, the configuration at the side-chain 2-position has no effect on affinity at the NET $(1 \mathrm{~S}, 2 \mathrm{~S}=1 \mathrm{~S}, 2 \mathrm{R}$; Table 1). Furthermore, the 1S diastereomers were less potent than the $1 \mathrm{R}, 2 \mathrm{~S}$ isomer but not the $1 \mathrm{R}, 2 \mathrm{R}$ isomer. As submitted above, we had expected both of the $1 \mathrm{R}$ compounds to be more "norepinephrine-like" and therefore more effective than both of the $1 \mathrm{~S}$ compounds, but this was not the case. These results suggest that the amino acid residues involved in ligand side-chain recognition within the NET substrate site may interact with one another and with the ligand in a complex way. Losses in affinity due to a suboptimal configuration at one side-chain carbon may be offset by gains in affinity at the other carbon; modifications to one site on the ligand can induce changes in affinity that are not simply additive with respect to the other site.

The bovine chromaffin vesicle is a well-accepted model for VMAT2mediated uptake into synaptic vesicles. The human and bovine VMAT2 exhibit similar pharmacological profiles for substrates and inhibitors (Schuldiner et al., 1995), making bovine vesicles useful for studying drugs that act at VMAT2. In the present study, only the 1R,2S HED isomer displayed halfmaximal inhibition at less than $30 \mu \mathrm{M}$ at VMAT2. As was seen at the DAT and SERT, the $2 \mathrm{~S}$ diastereomers were more effective than the $2 \mathrm{R}$ diastereomers, regardless of the configuration at the 1-position (Table 1), again suggesting that the substrate binding site is asymmetric even though the endogenous ligands are not themselves chiral. The low affinity of the HED compounds at VMAT2 is remarkable because VMAT2 is relatively indiscriminate with regard to arylalkylamine binding. Many structurally dissimilar molecules including tryptamine, histamine, serotonin, dopamine, 5-methoxy6-methyl-2-aminoindan, 3-methoxy-4-methylamphetamine, methamphetamine, and MDMA inhibit VMAT2-mediated neurotransmitter uptake in the nanomolar to low micromolar range (Rudnick and Wall, 1993; Finn and Edwards, 1997; Cozzi et al., 1999). 
Our findings have important implications for the design of PET radiotracers for imaging sympathetic neurons. In clinical studies, $1 \mathrm{R}, 2 \mathrm{~S}\left[{ }^{11} \mathrm{C}\right] \mathrm{HED}$ demonstrates a high initial myocardial uptake and a prolonged tissue clearance consistent with a slow turnover of the radiotracer (Schwaiger et al., 1990). The low tissue clearance of $1 \mathrm{R}, 2 \mathrm{~S}\left[{ }^{11} \mathrm{C}\right] \mathrm{HED}$ coupled with the short half-life of carbon-11 (20 min) prohibits the accurate determination of 1R,2S $\left[{ }^{11} \mathrm{C}\right] \mathrm{HED}$ release from nerve terminals and therefore does not permit the measurement (compartmental modeling) of norepinephrine tissue release based on 1R,2S [ $\left.{ }^{11} \mathrm{C}\right] \mathrm{HED}$ tissue kinetics. Our transporter affinity data may provide an explanation for the observed kinetic behavior of $1 \mathrm{R}, 2 \mathrm{~S}\left[{ }^{11} \mathrm{C}\right] \mathrm{HED}$ in human clinical studies as well as in an isolated rat heart model (DeGrado et al., 1993). The neuronal accumulation of a neurotransmitter or a drug analog is the net result of uptake, vesicular storage, and neuronal clearance processes such as metabolism. 1R,2S HED and its stereoisomers incorporate a methyl group $\alpha$ to the amino moiety (Fig. 1) which make these derivatives resistant to metabolism by monoamine oxidase (MAO) present in sympathetic nerve terminals. Additionally, due to its lower VMAT2 affinity as compared to norepinephrine, $1 \mathrm{R}, 2 \mathrm{~S}\left[{ }^{11} \mathrm{C}\right] \mathrm{HED}$ is more likely than norepinephrine to diffuse out of the neuron into the synapse where it can once again undergo neuronal uptake by the NET. Thus, the extended tissue half-life of $1 \mathrm{R}, 2 \mathrm{~S}$ $\left[{ }^{11} \mathrm{C}\right] \mathrm{HED}$ may be explained by its tendency to undergo indefinite neuronal recycling due to a combination of decreased metabolism, poor vesicular retention, and uptake via the NET. Given that all of the HED compounds are poor substrates for MAO and have low affinity for VMAT2, their relative affinity for the NET then becomes the dominant factor in neuronal recycling and clearance. Due to its lower NET affinity and better overall selectivity among all the monoamine uptake transporters (Table 1), the 1S,2R stereoisomer may be a better choice than the $1 \mathrm{R}, 2 \mathrm{~S}$ isomer for compartmental modeling by PET imaging.

In summary, there were modest but clear differences in potency among the test drugs based upon the stereochemical configuration of the HED sidechain. The 1R,2S HED stereoisomer was the preferred configuration at all the plasma membrane transporters and at VMAT2. Although each of the four monoamine carriers examined in this study is a unique protein, they all favor $1 \mathrm{R}, 2 \mathrm{~S}$ stereochemistry in substrate-like ligands, suggesting that the substrate binding pockets within these transporters are at least grossly similar. Our data also indicate that the $1 \mathrm{~S}, 2 \mathrm{R}$ HED isomer may be a better candidate for PET imaging than the $1 \mathrm{R}, 2 \mathrm{~S}$ stereoisomer due to its lower NET and VMAT2 affinities and better overall selectivity for the NET compared to the DAT, SERT, and VMAT2.

\section{Acknowledgements}

This work was supported in part by a grant from the National Alliance for Research on Schizophrenia and Depression (NVC) and by NIH grant NS33560 (MKS). We thank J. McKeel and M. Singer for their technical support. 


\section{References}

Allman KC, Stevens MJ, Wieland DM, Hutchins GD, Wolfe ERJ, Greene DA, Schwaiger M (1993a) Noninvasive assessment of cardiac diabetic neuropathy by carbon-11 hydroxyephedrine and positron emission tomography. J Am Coll Cardiol 22: $1425-1432$

Allman KC, Wieland DM, Muzik O, Degrado TR, Wolfe ERJ, Schwaiger M (1993b) Carbon-11 hydroxyephedrine with positron emission tomography for serial assessment of cardiac adrenergic neuronal function after acute myocardial infarction in humans. J Am Coll Cardiol 22: 368-375

Barker EL, Moore KR, Rakhshan F, Blakely RD (1999) Transmembrane domain i contributes to the permeation pathway for serotonin and ions in the serotonin transporter. J Neurosci 19: 4705-4717

Cozzi NV, Sievert MK, Shulgin AT, Jacob III P, Ruoho AE (1999) Inhibition of plasma membrane monoamine transporters by $\beta$-ketoamphetamines. Eur J Pharmacol 381: 63-69

Crespi D, Mennini T, Gobbi M (1997) Carrier-dependent and ca(2+)-dependent 5-ht and dopamine release induced by $(+)$-amphetamine, 3,4-methylendioxymethamphetamine, p-chloroamphetamine and (+)-fenfluramine. Br J Pharmacol 121: 17351743

DeGrado TR, Hutchins GD, Toorongian SA, Wieland DM, Schwaiger M (1993) Myocardial kinetics of carbon-11-meta-hydroxyephedrine: retention mechanisms and effects of norepinephrine. J Nucl Med 34: 1287-1293

Di Carli MF, Tobes MC, Mangener T, Levine AB, Muzik O, Chakroborty P, Levine TB (1997) Effects of cardiac sympathetic innervation on coronary blood flow. N Engl J Med 336: 1208-1215

Feany MB, Lee S, Edwards RH, Buckley KM (1992) The synaptic vesicle protein sv2 is a novel type of transmembrane transporter. Cell 70: 861-867

Finn JPr, Edwards RH (1997) Individual residues contribute to multiple differences in ligand recognition between vesicular monoamine transporters 1 and 2. J Biol Chem 272: $16301-16307$

Giros B, el Mestikawy S, Godinot N, Zheng K, Han H, Yang-Feng T, Caron MG (1992) Cloning, pharmacological characterization, and chromosome assignment of the human dopamine transporter. Mol Pharmacol 42: 383-390

Graham D, Langer SZ (1992) Advances in sodium-ion coupled biogenic amine transporters. Life Sci 51: 631-645

Gu H, Wall SC, Rudnick G (1994) Stable expression of biogenic amine transporters reveals differences in inhibitor sensitivity, kinetics, and ion dependence. J Biol Chem 269: 7124-7130

Huang X, Marona-Lewicka D, Nichols DE (1992) P-methylthioamphetamine is a potent new non-neurotoxic serotonin-releasing agent. Eur J Pharmacol 229: 31-38

Johnson RG (1987) Proton pumps and chemiosmotic coupling as a generalized mechanism for neurotransmitter and hormone transport. Ann NY Acad Sci 493: 162 177

Kanner BI (1994) Sodium-coupled neurotransmitter transport: structure, function and regulation. J Exp Biol 196: 237-249

Kitayama S, Shimada S, Xu H, Markham L, Donovan DM, Uhl GR (1992) Dopamine transporter site-directed mutations differentially alter substrate transport and cocaine binding. Proc Natl Acad Sci USA 89: 7782-7785

Liu Y, Peter D, Roghani A, Schuldiner S, Prive GG, Eisenberg D, Brecha N, Edwards RH (1992) A cdna that suppresses mpp+ toxicity encodes a vesicular amine transporter. Cell 70: 539-551

Monte AP, Marona-Lewicka D, Cozzi NV, Nichols DE (1993) Synthesis and pharmacological examination of benzofuran, indan, and tetralin analogues of 3,4(methylenedioxy)amphetamine. J Med Chem 36: 3700-3706 
1240 K. F. Foley et al.: Stereospecific inhibition of monoamine uptake transporters

Njus D (1983) The chromaffin vesicle and the energetics of storage organelles. J Auton Nerv Syst 7: 35-40

Pacholczyk T, Blakely RD, Amara SG (1991) Expression cloning of a cocaine- and antidepressant-sensitive human noradrenaline transporter. Nature 350: 350-354

Rosenspire KC, Haka MS, Van Dort ME, Jewett DM, Gildersleeve DL, Schwaiger M, Wieland DM (1990) Synthesis and preliminary evaluation of carbon-11-metahydroxyephedrine: a false transmitter agent for heart neuronal imaging. J Nucl Med 31: 1328-1334

Rothman RB, Ayestas MA, Dersch CM, Baumann MH (1999) Aminorex, fenfluramine, and chlorphentermine are serotonin transporter substrates. Implications for primary pulmonary hypertension. Circulation 100: 869-875

Rudnick G (1998) Ion-coupled neurotransmitter transport: thermodynamic vs. kinetic determinations of stoichiometry. Meth Enzymol 269: 233-247

Rudnick G, Clark J (1993) From synapse to vesicle: the reuptake and storage of biogenic amine neurotransmitters. Biochim Biophys Acta 1144: 249-263

Rudnick G, Wall SC (1993) Non-neurotoxic amphetamine derivatives release serotonin through serotonin transporters. Mol Pharmacol 43: 271-276

Schuldiner S, Steiner-Mordoch S, Yelin R, Wall SC, Rudnick G (1993) Amphetamine derivatives interact with both plasma membrane and secretory vesicle biogenic amine transporters. Mol Pharmacol 44: 1227-1231

Schuldiner S, Shirvan A, Linial M (1995) Vesicular neurotransmitter transporters: from bacteria to humans. Physiol Rev 75: 369-392

Schwaiger M, Kalff V, Rosenspire K, Haka MS, Molina E, Hutchins GD, Deeb M, Wolfe EJ, Wieland DM (1990) Noninvasive evaluation of sympathetic nervous system in human heart by positron emission tomography. Circulation 82: 457-464

Schwaiger M, Hutchins GD, Halff V, Rosenspire K, Haka MS, Mallette S, Deeb GM, Abrams GD, Wieland D (1991) Evidence for regional catecholamine uptake and storage sites in the transplanted human heart by positron emission tomography. J Clin Invest 87: 1681-1690

Van Dort ME (1999) Direct chromatographic resolution and isolation of the four stereoisomers of meta-hydroxyphenylpropanolamine. Chirality 11: 684-688

Van Dort ME, Tluczek L (2000) Synthesis and carbon-11 labeling of the stereoisomers of meta-hydroxyephedrine (hed) and meta-hydroxypseudoephedrine (hped). J Labelled Cpd Radiopharm 43: 603-612

Worrall DM, Williams DC (1994) Sodium ion-dependent transporters for neurotransmitters: a review of recent developments. Biochem J 297 (Pt 3): 425-436

Authors' address: Dr. N. V. Cozzi, Department of Pharmacology, Brody School of Medicine, East Carolina University, Greenville, NC 27858, U.S.A., e-mail: cozzin@mail.ecu.edu 